\section{Bavarian Nordic's prostate vaccine hits pay dirt}

A two-decade saga for prostate cancer vaccine PROSTVAC, starting with the now-defunct Therion Biologics, is paying off for Bavarian Nordic. The Kvistgaard, Denmark-based vaccine developer brokered a deal, potentially worth $\$ 975$ million, with Bristol-Myers Squibb (BMS) of New York to complete phase 3 testing of the vaccine for treating castration-resistant prostate cancer. Developed at a time when the immunobiology of cancer vaccines was poorly understood, the therapy failed in clinical trials in the early 2000s. But by choosing different clinical endpoints, Bavarian Nordic, which picked up the program from the National Cancer Institute in 2008, reported positive phase 2 results (8.5-month survival benefit). Milestone payments are pegged to the results of an ongoing phase 3 trial known as PROSPECT - the greater the survival benefit over that reported in phase 2 , the greater the payout. Bavarian Nordic's vaccine (rilimogene galvacirepvec-rilimogene glafolivec) follows the prime/boost model. An initial prostate-specific antigen (PSA) with three costimulatory molecules (TRICOM) vacciniafowlpox priming is followed by PSA-TRICOM fowlpox boosting doses. The vaccine faces competition from several recent approvals in the indication (Johnson \& Johnson's Zytiga (abiraterone acetate) and Medivation-Astellas' Xtandi (enzalutamide)). But the real excitement might come from combining Bavarian Nordic's vaccine for prostate cancer with BMS's immunotherapeutics Yervoy (ipilimumab, an antibody to CTLA4) or Opdivo (nivolumab, an antibody to PD-1).

\section{0-year-old EMA's birthday bash}

The European Medicines Agency (EMA) marked its coming of age on March 18 with a conference entitled "Patients at the heart of future innovation." Guido Rasi, principal adviser in charge of strategy at EMA, welcomed regulators, advisers, drug developers, investors and policymakers from across the globe, including Margaret Hamburg of the US Food and Drug Administration (FDA); Elias Zerhouni, president of global R\&D at Sanofi; and Mark Walport, chief scientific adviser to the UK government. Zerhouni credited the EMA for leading the way in clinical-trials transparency initiatives and the FDA for pioneering pathways to accelerate approvals for breakthrough drugs. But Zerhouni also remarked that the ultimate goal should not be to boost the number of drugs approved but to ensure drugs that affect great swathes of the population reach primary care, noting the trend toward approvals for rare disease therapies. The former NIH director also noted that regulatory convergence between agencies is sorely lacking. Despite efforts by the EMA and the FDA to collaborate, there is still a $22 \%$ discrepancy between the agencies' decisions to approve or reject drugs. Harmonization should become a priority, he urged. After all, drug development is a global business. Imagine international air travel if every country had its own airspace rules, Zerhouni prompted: who would board that plane?

\section{Nonbrowning GM apple cleared for market}

The US Department of Agriculture (USDA) on February 13 approved the first genetically modified (GM) apple developed to resist browning. The Arctic apple's go-ahead is a notable achievement for Canadian firm Okanagan Specialty Fruits, as the small biotech is one of the few to have successfully moved a GM plant through the regulatory process on its own. Indeed, two weeks after the apple's launch, Okanagan announced its acquisition by Germantown, Marylandbased Intrexon, a synthetic biology company. Okanagan's stockholders will receive $\$ 10$ million in upfront cash and $\$ 31$ million in Intrexon common stock. Industry observers now question whether the Arctic apple will carve a niche in the fruit tree industry or get caught up in the GM labeling debate.

Pre-cut fruit and vegetables are a growing trend in the food industry. "The [nonbrowning] trait will enable food service companies to cut and package the apples without adding browning inhibitors such as calcium ascorbate-an antioxidant that changes the flavor of the apple, says Neal Carter, founder of the Summerland, British Columbia-based Okanagan. About 22,000 trees will be planted in the US this spring, with the resulting fruit available in fall 2016 for product demonstration, he says. Okanagan has also applied for regulatory approval of its apple in Canada.

Browning is caused by polyphenol oxidases (PPOs) naturally present in fruit and vegetables. When fruit is cut or bruised, these enzymes catalyze the oxidation of polyphe- nols to quinones, causing oxidative browning. The damage is superficial but can affect the taste and texture of the apple as well as its cosmetic qualities. In the Arctic varieties, the GM apples were genetically engineered with a transgene that produces specific RNAs to silence the expression of at least four browning PPO genes. The apple RNA sequences were introduced into Granny Smith and Golden Delicious varieties, to bind complementary RNA and form a double strand. As RNA is single stranded, the double-stranded sequence is read as a mistake, and the plant's naturally occurring Dicer enzymes are sent to chop it up, resulting in no or significantly fewer PPO proteins being produced.

RNA interference (RNAi) was also used by JR Simplot of Boise, Idaho to silence PPO production in nonbrowning potatoes, which were approved by the USDA in November (Nat. Biotechnol. 33, 12-13, 2015). For that product, fragments of a single potato $\mathrm{PPO}$ gene were re-introduced into potato, activating the RNAi pathway. But unlike the apple, the potato's double-stranded RNA is formed by an inverted repeat transcribed in the tuber and processed into small interfering RNAs that ultimately silence their targets. JR Simplot's crop was also modified to have reduced acrylamide, which was achieved by using RNAi to silence the asparagine synthetase-1 gene (ASn1).

Apples that won't brown could make them more appealing to consumers and could also reduce waste by minimizing discarded apple

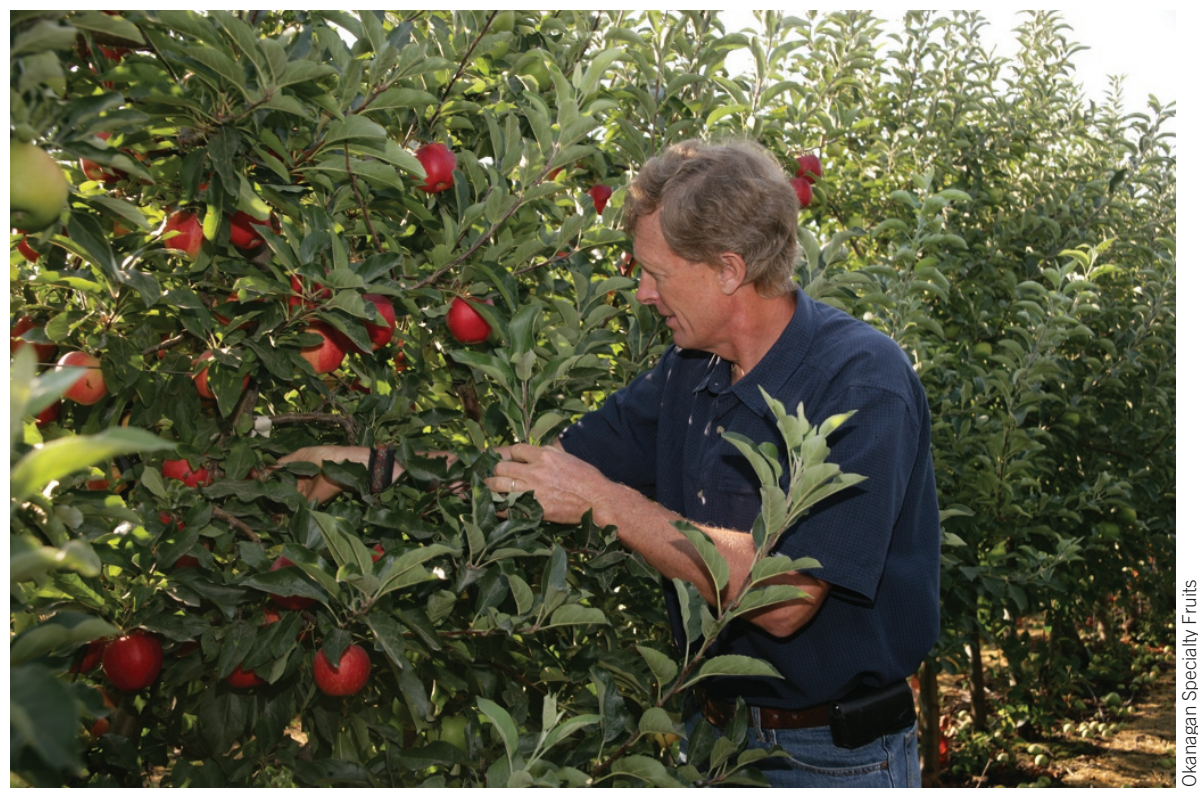

Apple grower Neal Carter founded Okanagan Specialty Fruits in 1996. 